\title{
Use of Artificial Neural Network to Optimize Osmotic Dehydration Process of Cashew from Cerrado (Anacardium Occidentale)
}

\author{
Rômulo Alves Morais \\ Food Engineering Department \\ Federal University of Tocantins \\ Palmas/Tocantins - Brazil
}

\author{
Denise Gomes Alves \\ Food Engineering Department \\ Federal University of Tocantins \\ Palmas/Tocantins - Brazil
}

\author{
Warley Gramacho da Silva \\ Computer Science Department \\ University Federal of Tocantins \\ Palmas/Tocantins - Brazil
}

\begin{abstract}
Food preservation uses many processes to improve quality and/or to extend shelf life of fruits and vegetables. One of these processes is osmotic dehydration that is a pretreatment before conventional drying. This process usually produces food with intermediary level of moisture. Osmotic dehydration can be optimized using mathematical modelling but it can present a bad adjustment to experimental data. Uses of Artificial Neural Network (ANN) in food processes is nowadays a goal for researchers because large applications and good adjustment to data.In this study it was used Artificial Neural Network (ANN) to optimize osmotic dehydration process of cashew from Cerrado. Variables of process were temperature $\left({ }^{\circ} \mathrm{C}\right)$, agitation (rpm) and solution concentration (\%) and responses were weight reduction (WR), water loss (WL) and solid gain (SG). Several configuration of ANN were tested and results showed that Multilayer Feedforward neural network (MLF) $3-7-3$ was the best one for this process.
\end{abstract}

\section{General Terms}

Artificial Neural Network, Osmotic Dehydration

\section{Keywords}

Cashew, Optimize, Dehydration

\section{INTRODUCTION}

Brazil is the third biggest producer of fruits but only $3 \%$ of fruits production goes to global fruit commerce [1].

Great consume and production of fruits are relevant for a healthy life mainly because their high content of vitamins, minerals and fibers.

Cerrado is a Brazilian bioma that has several fruit species with a great potential for agricultural production. These fruits are consumed by local population in different forms such as juices, jellies, ice creams and licors [1]. Most of these processed fruits goes to international commerce [1]

Osmotic dehydration (OD) process has been studied for many researchers all over the world. It is a pretreatment before conventional drying to reduce time of process and to keep organoleptic characteristics of food. OD process presents data of weight reduction, water loss and solid gain. can also produce food of intermediary moisture. Mass transfer is evolved in this process because samples are immerged in a solution with high concentration of one or more solutes [2], [3]. Sugar can provide a good condition of process when fruits are evolved because produce a high water loss and low solid gain [3].

To optimize drying processes some authors are using Artificial Neural Networks (ANNs) [4], [5], [6] and [7]. This computer tool can be a good alternative to predict behavior of food when submitted to osmotic dehydration process.

The objective of this work was to evaluate influences of osmotic dehydration process on chemical and physical characteristics of cashew from Cerrado and to obtain experimental data of process (Weight Reduction, Water Loss and Solid Gain) to test ANN for optimization of osmotic dehydration process.

\section{MATERIAL AND METHODS}

\subsection{Material}

Cashew from Cerrado was bought from local market. They were selected, washed and put on identified plastic bags.

\subsection{Methods}

2.2.1 Fruit Characterization. Analysis of moisture content, $\mathrm{pH}$, titrable acidity, color, carotenoids, vitamin $\mathrm{C}$, vitamin $\mathrm{A}$, reducing and non-reducing sugars, lipids contents, protein contents and fibers were carried out. Samples were analyzed in triplicate. Methodologies of analysis were made according to Adolfo Lutz Institute (2005) [8]. Statistical analyses were made using Assistat software with Tukey test for $5 \%$ of confidence.

2.2.2 Osmotic Dehydration. Osmotic dehydration process was realized using a Planning Design to optimize process. Variables for this were: 
Table 1. Independent variables for osmotic dehydration process.

\begin{tabular}{cccc}
\hline Run & Temp. $\left({ }^{\circ} \mathbf{C}\right)$ & Concentration (\%) & Agitation (rpm) \\
\hline \hline 01 & 40 & 20 & 80 \\
\hline 02 & 40 & 20 & 120 \\
\hline 03 & 40 & 50 & 80 \\
\hline 04 & 40 & 50 & 120 \\
\hline 05 & 50 & 20 & 80 \\
\hline 06 & 50 & 20 & 120 \\
\hline 07 & 50 & 50 & 80 \\
\hline 08 & 50 & 50 & 120 \\
\hline 09 & 45 & 35 & 65 \\
\hline 10 & 45 & 35 & 65 \\
\hline 11 & 45 & 35 & 65 \\
\hline 12 & 30 & 35 & 65 \\
\hline 13 & 45 & 10 & 65 \\
\hline 14 & 45 & 35 & 80 \\
\hline 15 & 60 & 35 & 65 \\
\hline 16 & 45 & 60 & 65 \\
\hline 17 & 45 & 35 & 130 \\
\hline
\end{tabular}

Analysis of weight reduction (WR), water loss (WL) and solid gain (SG) were calculated using equations below:

$$
\begin{gathered}
W R(\%)=\frac{\left(M_{o} \times U_{o}\right)-\left(M_{t} \times U_{t}\right)}{M_{o}} . \\
W L(\%)=\frac{\left(M_{t} \times B_{t}\right)-\left(M_{o} \times B_{o}\right)}{M_{o}} . \\
S G(\%)=\frac{M_{o}-M_{t}}{M_{o}} \times 100 .
\end{gathered}
$$

Where:

-WR $(\%)=$ weight reduction, $\%(\mathrm{w} / \mathrm{w})$;

-WL $(\%)=$ water loss, $\%(\mathrm{w} / \mathrm{w})$;

-SG $(\%)=$ solid gain, $\%(\mathrm{w} / \mathrm{w}) ;$

$-M_{o}=$ mass of fruit on time $t=0$, grams;

$-M_{t}=$ Mass of treated fruit on time $t$, grams;

$-B_{o}={ }^{\circ}$ Brix of fruit on time $t=0$;

$-B_{t}={ }^{\circ}$ Brix of treated fruit on time $t$;

$-U_{o}=$ Moisture content on time $t=0, \%$ in wet basis;

$-U_{t}=$ Moisture content of treated fruit on time $t, \%$ wet basis.

Statistical analyses for osmotic dehydration were made using Statistica 7.0 software.

2.2.3 Artificial neural network modeling. There are many neural network models. A widely used ANN model for prediction and control of food processing operations is a Multilayer Feedforward neural network (MLF)[7]. A MLF consists of (i) an input layer with neurons representing input variables to the problem, (ii) an output layer with neuron(s) representing the dependent variable(s), and (iii) one or more hidden layers containing neuron(s) to help capture the nonlinearity in the system (Fig. 1).

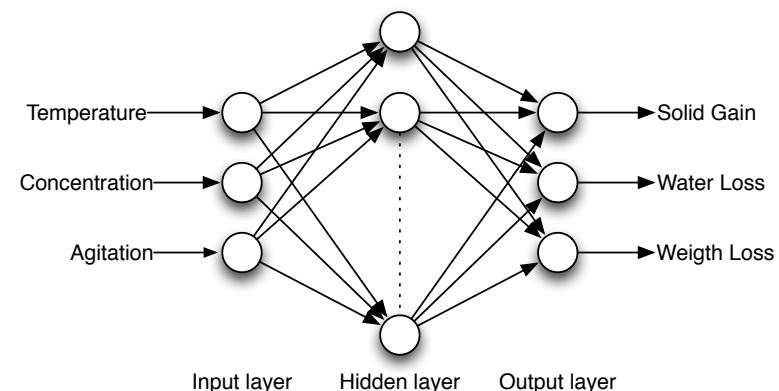

Fig. 1. Multilayer feedforward neural network architecture with one hidden layer for prediction solid gain, water loss and weight reduction of osmotically dehydrated of Cashew from Cerrado (Anacardium occidentale).

In this study, the operational variables of osmotic process of cashew from Cerrado (Anacardium occidentale) (temperature, concentration, and agitation) were used as inputs, and solid gain, water loss, and weight reduction were considered as outputs. In the hidden layer, was chosen to be used a hyperbolic tangent activation function (Eq. 4).

$$
\tanh =\frac{e^{x}-e^{-x}}{e^{x}+e^{-x}} .
$$

To improve the behavior of the MLF, due to the different ranges of each input and each output, both input and output data were normalized before feeding into the network according to Eq. 5

$$
\phi_{i n o r m}=\frac{\phi_{i}-\min \left(\phi_{i}\right)}{\max \left(\phi_{i}\right)-\min \left(\phi_{i}\right)}
$$

where $\phi_{i}$ is $i$-th case.

The performance of the networks was measured by linear correlation coefficient $\left(R^{2}\right.$, Eq. 6), which compares the values predicted by the artificial neural networks and the experimental values as follows.

$$
R^{2}=\sum_{i=1}^{N} \frac{\left(\psi_{i_{\text {pred }}}-\bar{\psi}_{i_{\text {exp }}}\right)}{\left(\psi_{\text {i exp }}-\bar{\psi}_{i_{\text {exp }}}\right)^{2}}
$$

where $\psi_{\text {exp }}$ is experimental value and $\psi_{\text {pred }}$ is ANN predicted value.

\section{RESULTS AND DISCUSSION}

\subsection{Fruit characterization}

On Table 2 it can be observed fruit characterization of fruit before osmotic dehydration process. 
Table 2. Experimental data of fruit before osmotic dehydration process.

\begin{tabular}{c|c|c|c}
\hline Analyses & Avg \& Std. Deviation & CV(\%) & F \\
\hline \hline DPPH & $7.98 \pm 0.02$ & 0.33 & 0.5800 \\
\hline $\mathrm{pH}$ & $3.70 \pm 0.54$ & 13.27 & 1.9571 \\
\hline Carotenoids & $0.33 \pm 0.01$ & 4.25 & 1.8991 \\
\hline Lipids & $3.28 \pm 0.44$ & 10.72 & 3.4841 \\
\hline Moisture content & $91.24 \pm 0.50$ & 0.60 & 0.3373 \\
\hline Titrable acidity & $4.20 \pm 0.41$ & 11.64 & 1.1463 \\
\hline Ashes & $0.30 \pm 0.04$ & 1.51 & 0.3804 \\
\hline Reducing sugars & $2.55 \pm 0.10$ & 4.21 & $10.24^{*}$ \\
\hline Non-reducing sugars & $2.012 \pm 0.08$ & 0.51 & $0.0162^{*}$ \\
\hline significant of 5\% of probability.
\end{tabular}

In natura fruit presented high moisture content (91.24\%) that is consistent for fruits and vegetable. Values of $\mathrm{pH}(3.70 \pm 0.54)$, Titrable acidity $\left(4.20 \pm 0.41 \mathrm{mLg}^{-1}\right)$ and reducing sugars $(2.55 \pm$ $\left.0.10 \mathrm{mg} 100 \mathrm{~g}^{-1}\right)$. These values were different from [9] working with fruits from Cerrado and [10] working with cashew from Cerrado. This behavior can be explained by the fact that fruits and vegetables suffer influence of weather changes, soil components, hours of exposition to sun and crop treatments.

Comparing both Tables (2 and 3 it can be observed that variations occurred for moisture, $\mathrm{pH}$ and sugar contents. Osmotic dehydration process was efficient to reduce moisture content according to solution concentration increase. Value of $\mathrm{pH}$ increased from 3.70 (raw material) to $4.16\left(60^{\circ}\right.$ Brix solution concentration) but did not change its acidity character. Reducing sugars was 2.55 then had increases when solution concentration increased. Removal of moisture can concentrate other components like sugars. Carotenoids, lipids and ashes were not influenced by OD process. This behavior was observed by [11] working with pineapple in solution with sucrose.

\subsection{Osmotic dehydration process - Effects of the process on response variables}

Tables 4, 5 and 6 presents Statistical analyses of responses (WR, $\mathrm{WL}$ and $\mathrm{SG})$.

3.2.1 Weight Reduction. Table 4 presents results for weight reduction.

Table 4. Statistical analyses of weight reduction (WR).

\begin{tabular}{|c|c|c|c|c|}
\hline Factors & Effect \& Std Dev & $\mathbf{t}$ & $\mathbf{p}$ & \\
\hline Global Average & $13.371 \pm 1.423$ & 9.39 & 0.011 & \multirow{10}{*}{$R^{2}=0,78$} \\
\hline Temperature (L) & $9.197 \pm 1.297$ & 7.09 & 0.019 & \\
\hline Temperature (Q) & $-0.141 \pm 0.428$ & -0.33 & 0.772 & \\
\hline Concentration (L) & $-1.790 \pm 1.352$ & -1.32 & 0.317 & \\
\hline Concentration $(\mathrm{Q})$ & $-6.921 \pm 1.322$ & -5.23 & 0.035 & \\
\hline Agitation (L & $9.451 \pm 1.596$ & 5.92 & 0.027 & \\
\hline Agitation (Q) & $1.880 \pm 3.679$ & 0.511 & 0.660 & \\
\hline $1 \times 2$ & $-3.625 \pm 1.566$ & -2.314 & 0.147 & \\
\hline $1 \times 3$ & $6.554 \pm 1.441$ & 4.55 & 0.045 & \\
\hline $2 \times 3$ & $-7.495 \pm 1.695$ & -4.42 & 0.048 & \\
\hline
\end{tabular}

For weight reduction (WR) the most significant variables were temperature and agitation and interactions between temperature and agitation, solution concentration and agitation. According to [11] increase of temperature affects WR of osmotically dehydrated cashew apples. Negative values for solution concentration can be explained by the fact that higher concentrations of solution can formed a layer on fruit. This layer can avoid mass transference.

3.2.2 Water Loss. Table 5 presents results for water loss. Water loss (WL) was affected by temperature and agitation. Quadratic variable of solution concentration was also significant. These results were similar to [2] working with pineapple and [11] with pear cubes. Quadratic factors of temperature, solution concentration and interaction of solution concentration and agitation presented negative values. These negative values indicate that an increase of variables caused a decrease of response. For WL regression coefficient had an improvement ( 0.81$)$ that indicated a good adjust to experimental data.

Table 5. Statistical analyses of water loss (WL).

\begin{tabular}{c|c|c|c|c}
\hline Factors & Effect \& Std Dev & t & p & \\
\hline \hline Global Average & $33.36 \pm 0.904$ & 36.91 & $0,001^{*}$ & \\
\hline Temperature (L) & $4.97 \pm 0.824$ & 6.03 & $0,026^{*}$ & \\
Temperature (Q) & $-0.23 \pm 0.272$ & -0.85 & 0.483 & \\
\hline Concentration (L) & $0.76 \pm 0.859$ & 0.88 & 0.472 & \\
Concentration (Q) & $-7.57 \pm 0.840$ & -9.01 & $0,012^{*}$ & \multirow{2}{*}{$R^{2}=0,81$} \\
\cline { 1 - 4 } Agitation (L & $4.41 \pm 1.014$ & 4.34 & $0,049^{*}$ & \\
Agitation (Q) & $6.42 \pm 2.336$ & 2.74 & 0.111 & \\
\cline { 1 - 3 } 1 x2 & $-3.71 \pm 0.995$ & -3.72 & 0.065 & \\
$1 \times 3$ & $3.19 \pm 0.915$ & 3.48 & 0.073 & \\
$2 \times 3$ & $-8.76 \pm 1.076$ & -8.14 & $0.015^{*}$ & \\
$* p<0,05$, L=linear, Q=quadratic, interactions are made for linear variables.
\end{tabular}

3.2.3 Solid Gain. The most significant factors for solid gain (Table 6 were temperature, solution concentration and agitation. It can be observed that temperature and agitation had negative value that could be explained because high variables values can promote a tissue damage of skin so they become permeable to mass transference. This behavior was observed by [12] working with pineapple cubes.

Statistical analyses showed that WR,WL and SG were influenced by temperature, solution concentration and agitation of samples and they were according other authors working OD [2], [9] and [11].

Table 6. Statistical analyses of solid gain (SG).

\begin{tabular}{|c|c|c|c|c|}
\hline Factors & Effect \& Std Dev & $\mathbf{t}$ & $\mathbf{p}$ & \\
\hline Global Average & $\overline{c 19.50 \pm 0.498}$ & 39.15 & $0.001^{*}$ & \multirow{10}{*}{$R^{2}=0,99$} \\
\hline Temperature (L) & $-2.46 \pm 0.454$ & -5.41 & $0.033^{*}$ & \\
\hline Temperature (Q) & $0.09 \pm 0.150$ & 0.62 & 0.601 & \\
\hline Concentration (L) & $27.85 \pm 0.473$ & 58.84 & $0.000^{*}$ & \\
\hline Concentration $(\mathrm{Q})$ & $1.90 \pm 0.463$ & 4.11 & 0.054 & \\
\hline Agitation (L & $-2.49 \pm 0.559$ & -4.45 & $0.047^{*}$ & \\
\hline Agitation (Q) & $-0.85 \pm 1.288$ & -0.66 & 0.576 & \\
\hline $1 \times 2$ & $-0.31 \pm 0.548$ & -0.57 & 0.629 & \\
\hline $1 \times 3$ & $-1.39 \pm 0.504$ & -2.76 & 0.110 & \\
\hline $2 \times 3$ & $0.13 \pm 0.593$ & 0.23 & 0.841 & \\
\hline
\end{tabular}

Statistical analyses showed that WR,WL and SG were influenced by temperature, solution concentration and agitation of samples and they were according other authors working OD [12], [11] and [7]. 


\subsection{Artificial neural network optimization}

In this study an ANN was used to optimize osmotic dehydration process. This ANN was configured using three input variables (temperature, solution concentration and agitation), three output variables (weight reduction, water loss and solid gain) and then hidden layers were tested to adjust the best one for predicting process (Fig. 11). Used MLFs are marked with following notation, MLF followed by number of inputs, number of neurons in the hidden layer, and the number of outputs.

Hidden layers varied from 2 to 9 . Table 7 presents results of $R^{2}$ between experimentally measured and ANN outputs. It can be verified that if hidden layers were only 2 , regression coefficient $\left(R^{2}\right)$ was inferior of $R^{2}$ of statistical analyses for all responses, but when hidden layers are increased then $R^{2}$ of ANN was better than of statistical analyses. Uses of 9 hidden layers were not more efficient than 7 so the best configuration of ANN was MLF $3-7-3$.

Table 7. $R^{2}$ between experimentally measured and ANN outputs.

\begin{tabular}{l|c|c|c}
\hline ANN name & WR & WL & SG \\
\hline \hline MLF 3-2-3 & 0.64 & 0.68 & 0.89 \\
MLF 3 - 3-3 & 0.90 & 0.84 & 0.95 \\
MLF 3 - 5-3 & 0.94 & 0.94 & 0.96 \\
MLF 3 - 7 - 3 & 0.98 & 0.97 & 0.99 \\
MLF 3 - 9-3 & 0.97 & 0.97 & 0.99 \\
\hline
\end{tabular}

In Figure 2 all configurations of ANN to WR was plotted and showed that the best configuration of ANN was MLF $3-7-3$ because their values are closed to perfect prediction line [13].

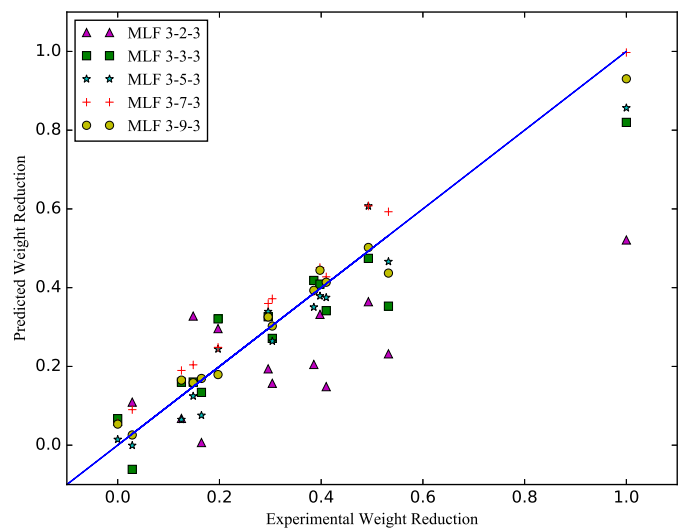

Fig. 2. Normalized Weigth Reduction (WR) model prediction performance for differents MLF configuration.

For WL and SG (Figures 3 and 4) it can be observed that same behavior of WR, the best adjust to experimental data is MLF $3-$ $7-3$.

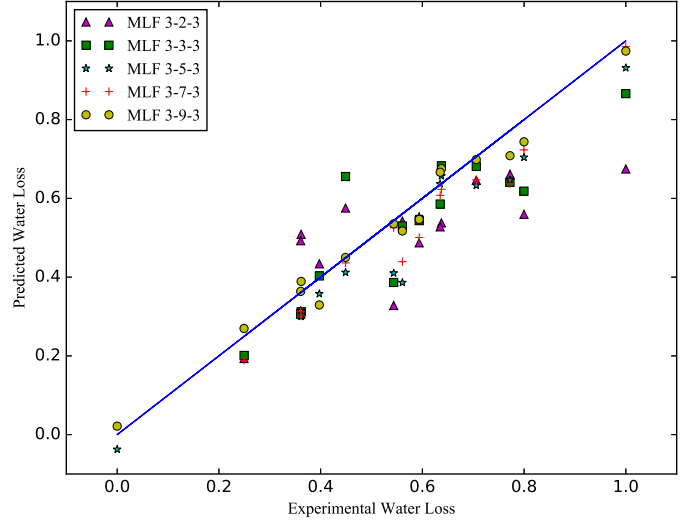

Fig. 3. Normalized Water Loss (WL) model prediction performance for differents MLF configuration.

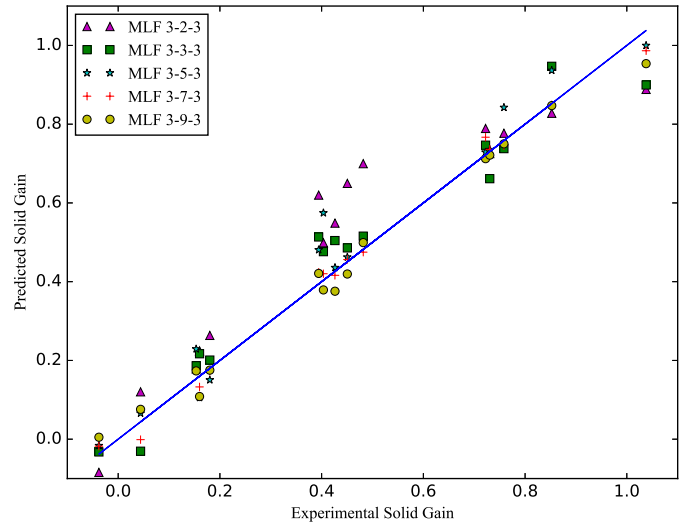

Fig. 4. Normalized Solid Gain (SG) model prediction performance for differents MLF configuration

In Figures 5,6 and 7 it was observed ANN configuration with 7 neurons on hidden layer (MLF $3-7-3$ ). They presented a better adjust to experimental data. Regression coefficient $\left(R^{2}\right)$ of WR was 0.98 , for WL was 0.97 and for SG was 0.99 . [13] working with papaya varied hidden layer from 3 to 10 and observed that when more hidden layers can adjust data to experimental processes more than other statistical tools. 


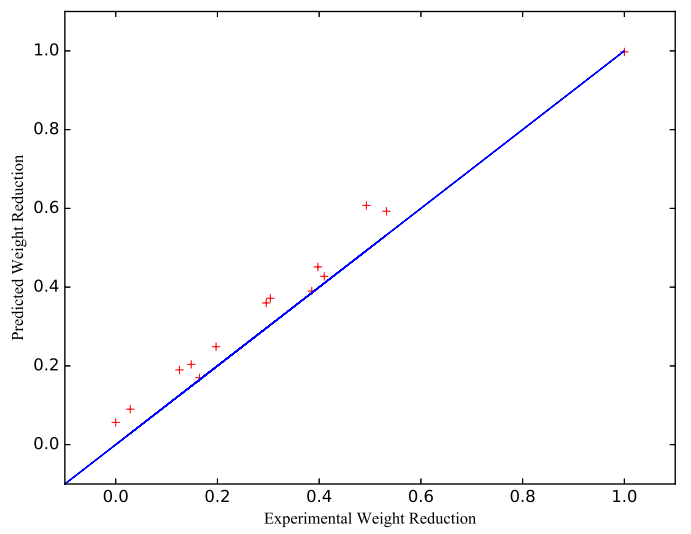

Fig. 5. Experimental vs. predicted values for weigth reduction of osmotically dehydrated Cashew from Cerrado by optimum ANN configuration MLF $3-7-3\left(R^{2}=0.98\right)$.

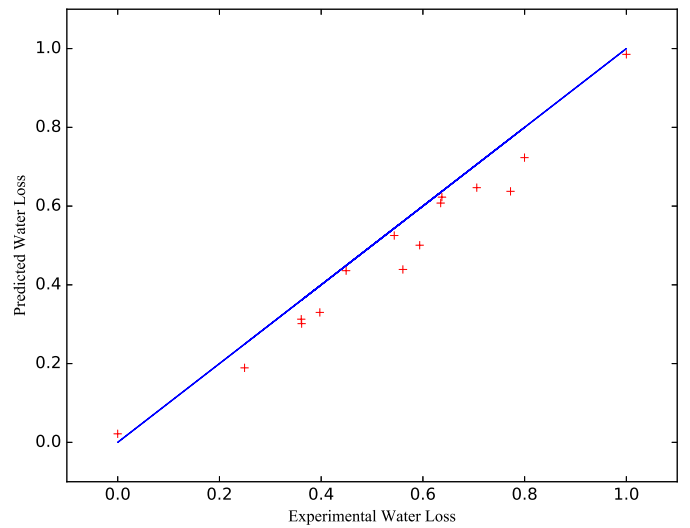

Fig. 6. Experimental vs. predicted values for water loss of osmotically dehydrated Cashew from Cerrado by optimum ANN configuration MLF $3-7-3\left(R^{2}=0.97\right)$.

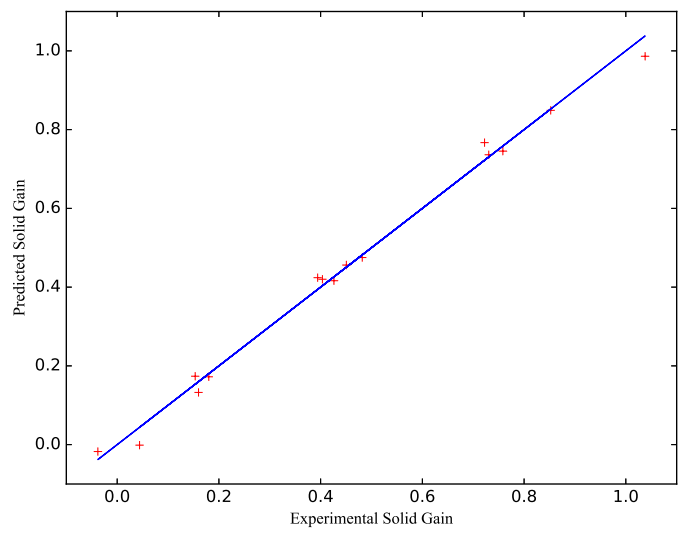

Fig. 7. Experimental vs. predicted values for solid gain of osmotically dehydrated Cashew from Cerrado by optimum ANN configuration MLF $3-7-3\left(R^{2}=0.99\right)$.

ANN is an artificial intelligence that can learn with process so they are important to predict behavior of biological material. For osmotic dehydration process they provide a good adjust to experimental data and could predict the process improving values of regression coefficient. Other authors working with ANN had good prediction of processes of drying [4], [5], [7] and [13].

\section{CONCLUSION}

Osmotic Dehydration (OD) process can be effective to reduce moisture content and produce intermediary moisture level foods. This behavior is important for food stability. Temperature, concentration and agitation influenced Weight Reduction (WR), Water Loss (WL) and Solid Gain (SG).

Statistical analyses showed that $R^{2}$ were low for WR (0.78) WL (0.81). Only for SG it was high (0.99). After using Artificial Neural Network (ANN) they became higher than 0.90 . This behavior showed that ANN can predict better conditions for OD process.

ANN configurations were tested from 2 hidden layers to 9 . For only 2 hidden layers $R^{2}$ were below statistical analyses. Nine hidden layers did not present an improvement to OD process, so the best configuration to OD process of cashew from Cerrado was Multilayer Feedforward neural network (MLF) $3-7-3$.

Use of ANN to optimize osmotic dehydration of cashew from Cerrado was efficient and presented a good adjust to experimental data. ANN is a good tool for OD processes and can help food production for industry.

\section{ACKNOWLEGMENTS}

The authors would like to thank Prof. Dr. Glêndara Martins who have contributed towards development of the project.

\section{REFERENCES}

[1] M. Treichel. Brazilian Fruticulture Directory. Santa Cruz do Sul: Editora Gazeta, 2016.

[2] Keila S. Silva, Milena A. Fernandes, and Maria A. Mauro. Osmotic dehydration of pineapple with impregnation of sucrose, calcium, and ascorbic acid. Food and Bioprocess Technology, 7(2):385-397, 2014. 
[3] T. H. L. Silva, B. F. A. Protsio, O. S. Silva, J. C. Silva., and T. S. Porto. Desidratao osmótica do tomate em solucões ternárias como pré-tratamento para secagem. $R e$ vista Brasileira Agrotecnologia, 5:72-75, 2015.

[4] N. J. Singh and R. K. Pandey. Neural network approaches for prediction of pistachio drying kinetics. Agric. Eng. Int. J., 13(1):1-12, 2011.

[5] M. Mokhtarian and H. Tavakolipour. The application of neural network method for the prediction of the osmotic factors of crookneck squash. Journal of Food Biosciences and Technology, 6(2):23-30, 2016.

[6] T. P. K. Murthy and B. Manohar. Hot air drying characteristics of mango ginger: Prediction of drying kinetics by mathematical modeling and artificial neural network. J. Food Sci. Technol, 51(12):3712-3721, 2014.

[7] S. Lertworasirikul and S. Saetan. Artificial neural network modeling of mass transfer during osmotic dehydration of kaffir lime peel. Journal of Food Engineering, 98(2):214-223, 2010.

[8] Adolfo Lutz Institute. Analitical Methods. Chemical and Physical Analysis for Food. 4 ed., São Paulo - SP, 2005.

[9] G. G. Santos M. R. Silva, D. B. C. L. Lacerda and D. M. D. O. Martins. Caracterizao qumica de frutos nativos do cerrado. Citncia Rural, 38(6):1790-1793, 2008.

[10] T. L. Cunha M. C. P. Martins and M. R. Silva. Efeito das condies da desidratao osmtica na qualidade de passas de cajudo-cerrado. Citncia e Tecnol. Aliment., 28:158-165, 2008.

[11] K. O. Falade, T. O. Akinwale, and O. O. Adedokun. Effect of drying methods on osmotically dehydrated cashew apples. European Food Research and Technology, 216(6):500-504, 2003.

[12] PM Azoubel. Optimisation of osmotic dehydration of cashew apple (Anacardium occidentale L.) in sugar solutions. Sage Publications Ltd, 2003.

[13] J. Prakash Maran, V. Sivakumar, K. Thirugnanasambandham, and R. Sridhar. Artificial neural network and response surface methodology modeling in mass transfer parameters predictions during osmotic dehydration of carica papaya 1. Alexandria Engineering Journal, 52(3):507 - 516, 2013. 
Table 3. Experimental data after osmotic dehydration process with average and standard deviation

\begin{tabular}{l|ccccc}
\hline Analysis & $10^{\circ}$ Brix & $20^{\circ}$ Brix & $35^{\circ}$ Brix & $50^{\circ}$ Brix & $60^{\circ}$ Brix \\
\hline \hline DPPH & $7.99 \pm 0.5$ & $8.001 \pm 0.5$ & $8.032 \pm 0.5$ & $8.103 \pm 0.5$ & $8.101 \pm 0.5$ \\
\hline $\mathrm{pH}$ & $3.87 \pm 0.02$ & $4.08 \pm 0.02$ & $4.10 \pm 0.02$ & $4.11 \pm 0.02$ & $4.16 \pm 0.02$ \\
\hline Carotenoides & $0.333 \pm 0.05$ & $0.339 \pm 0.05$ & $0.336 \pm 0.05$ & $0.343 \pm 0.05$ & $0.351 \pm 0.05$ \\
\hline Lipides & $3.321 \pm 0.01$ & $3.395 \pm 0.01$ & $3.428 \pm 0.01$ & $3.771 \pm 0.01$ & $3.567 \pm 0.01$ \\
\hline Moisture content & $72.3 \pm 1.5$ & $68.4 \pm 1.6$ & $63.5 \pm 1.6$ & $65.9 \pm 1.8$ & $61.3 \pm 1.7$ \\
\hline Titrable acidity & $4.10 \pm 0.001$ & $4.11 \pm 0.01$ & $4.24 \pm 0.01$ & $4.18 \pm 0.01$ & $4.30 \pm 0.01$ \\
\hline Ashes & $0.353 \pm 0.5$ & $0.378 \pm 0.5$ & $0.361 \pm 0.5$ & $0.389 \pm 0.5$ & $0.404 \pm 0.5$ \\
\hline Reducing Sugars & $15.34 \pm 0.5$ & $18.87 \pm 0.5$ & $20.55 \pm 0.5$ & $23.78 \pm 0.5$ & $25.01 \pm 0.5$ \\
\hline Non Reducing Sugars & $13.43 \pm 0.5$ & $14.98 \pm 0.5$ & $16.73 \pm 0.5$ & $19.86 \pm 0.5$ & $21.34 \pm 0.5$ \\
\hline
\end{tabular}

